\title{
Evaluation of the Direct Interaction between Amino Acids and Glutathione-Coated CdTe Quantum Dots and Application in Urinalysis for Histidine Determination
}

\author{
Leila S. V. Barbosa, ${ }^{a}$ Leonardo S. G. Teixeira, ${ }^{a, b}$ Maria G. A. Korn ${ }^{\oplus *, a, b}$ and \\ Rodolfo M. M. Santana ${ }^{\circledR} * a$ \\ ${ }^{a}$ Departamento de Química Analítica, Instituto de Química, Universidade Federal da Bahia (UFBA), \\ Campus Universitário de Ondina, 40170-115 Salvador-BA, Brazil \\ ${ }^{b}$ Instituto Nacional de Ciência e Tecnologia (INCT em Energia e Ambiente), Instituto de Química, \\ Universidade Federal da Bahia (UFBA), Campus Universitário de Ondina, \\ 40170-115 Salvador-BA, Brazil
}

\begin{abstract}
The present work aimed to direct amino acid (AA) sensing by quantum dots (QD) and development of an analytical method for potential fast clinical tests. Notably, AA with a positive charge or neutral polar chains, namely L-histidine (His) and L-threonine (Thr), responded to glutathione-coated CdTe (GSH-CdTe) $(\Delta \mathrm{F} \leq 90 \%$, variation of fluorescence intensity). However, in ammoniacal buffer $\left(0.25 \mathrm{~mol} \mathrm{~L}^{-1}\right)$ at $\mathrm{pH} 8.0,2.2 \mathrm{~nm} \mathrm{GSH}-\mathrm{CdTe}$ responded only to His. Static quenching with complex association constant $\left(\mathrm{K}_{\mathrm{sv}}\right)$ varying from 2.81 to $0.94\left(10 \mathrm{~L} \mathrm{~mol}^{-1}\right)$ as well as van der Waals forces and/or hydrogen bonding were predicted for His-QD quenching mechanism and binding type. Additionally, thermodynamic parameters as $\Delta \mathrm{H}=-76.5 \mathrm{~kJ} \mathrm{~mol}^{-1}$ (enthalpy), $\Delta \mathrm{S}=-227.4 \mathrm{~J} \mathrm{~K}^{-1} \mathrm{~mol}^{-1}$ (entropy) and $\Delta \mathrm{G}$ from -9.8 until $-6.4 \mathrm{~kJ} \mathrm{~mol}^{-1}$ (Gibbs free energy) at 20 to $35^{\circ} \mathrm{C}$ were estimated by van't Hoff equation. Under optimal conditions, the developed method presented a linear range from 0.42 to $35 \mathrm{mmol} \mathrm{L}^{-1}$ (with correlation coefficient (r) of $0.9970, \mathrm{n}=7$ ), good precision (relative standard deviations (RSD) $<2.5 \%$ for 2.5 and $20 \mathrm{mmol} \mathrm{L}^{-1} ; \mathrm{n}=6$ ) and limit of detection $1.6 \times 10^{-4} \mathrm{~mol} \mathrm{~L}^{-1}\left(0.025 \mathrm{mg} \mathrm{mL}^{-1}\right)$. Recovery tests were performed on artificial urine and human urine samples with recoveries ranging from 78.7 to $127.6 \%$.
\end{abstract}

Keywords: amino acids, histidine, urine, quantum dots, clinical test

\section{Introduction}

Amino acids (AAs) are the main constituents of proteins; they are responsible for repairing tissues, nails and hair and for the production of hormones, neurotransmitters and enzymes, being that all of which are responsible for coordinating organic functions in human metabolism. The accumulation, or lack thereof, of these AAs can lead to serious deleterious health effects. ${ }^{1}$ The AA lack can cause problems in multiple metabolic functions and affect immunity, growth and development. ${ }^{2}$ On the other hand, AA accumulation is associated with a genetic fault that causes problems in protein or enzymatic synthesis, which are the so-called aminoacidopathies. One of the common AA metabolic disorders is histidinemia caused by histidine (His) accumulation that could lead a several developmental disturbs like hyperactivity, mental retardation and speech

*e-mail:mgkorn23@gmail.com; rodolfo.magalhaes@ufba.br difficulties, especially in infant kids. ${ }^{3}$ This accumulation can be diagnosed and monitored by clinical analytical tests using blood and urine samples. ${ }^{4}$

Beyond the clinical tests, several methods have been developed for the AA determination; they mostly employ high-performance liquid chromatography (HPLC). ${ }^{5}$ Alternative methods have been developed for the AA determination in biological fluids and food samples; these analyses adopt ultra-performance liquid chromatography (UPLC), ${ }^{6,7}$ liquid chromatography coupled to mass spectrometry (LC-MS), ${ }^{8,9}$ gas chromatography coupled to mass spectrometry (GC-MS) ${ }^{10,11}$ and capillary electrophoresis coupled to mass spectrometry (CE-MS). ${ }^{12}$ However, these methods can show some hindrances, such as high maintenance costs, laborious sample pre-treatment and low analytical throughput, despite their good sensitivity and accuracy.

Luminescent methods have emerged as an alternative for AA determination due to operational simplicity, 
great sensitivity and precision. Within this panorama, semiconductor quantum dots (QD) should be highlighted as photoluminescent probes. ${ }^{13-16}$ The optical QD properties, including photostability, photosensitivity and luminescence, make them highly efficient fluorophores. ${ }^{17}$ Thus, QD can be used as photo sensors to determine many compounds, such as metal ions, ${ }^{18,19}$ proteins, ${ }^{20}$ nucleic acids ${ }^{21}$ and AAs. ${ }^{22-24}$

The QD photoluminescence results from the recombination of an electron-hole pair (Bohr exciton) that could be affected through chemical or physical interactions established between a given chemical specie and nanocrystal surface by changing the electron-hole recombination efficiency. In this manner, target species sensing by QD is a surface-dependent phenomenon, which can be performed by direct or indirect (e.g., a turn-off/turn-on approach) probe interaction. ${ }^{25}$

Turn-off/turn-on approach is the strategy that has been frequently adopted for the development of QD analytical methods aimed at AA determination due to the well-known QD interaction with many cations, ${ }^{26}$ as well as other species like $\mathrm{KI}_{3},{ }^{27}$ porphyrins ${ }^{28}$ and specific interactions of these species with AAs. For example, arginine was determined in drug injections and blood plasma samples by exploiting the internal filter effect (IFE) caused by gold nanoparticles (AuNP) on the thioglycolic-coated CdTe QD fluorescence. In the process, the AuNPs acted as a quencher for the QD fluorescence, and cysteine was responsible for the turn-on effect due to AuNP complexation. ${ }^{29}$ Another example is the use of a histidine sensor based on a homocysteinemodulated CdTe QD (Hcy-CdTe QD). Photoluminescent sensor modulation was performed in the presence of $\mathrm{Ni}^{\mathrm{iI}}$ and His because the QD emission signals were recovered due to the fact that the $\mathrm{Ni}^{\mathrm{II}}$-His interaction was more efficient than the $\mathrm{Ni}^{\mathrm{II}}$-Hcy interaction. ${ }^{30}$ Recently, copperfunctionalized carbon quantum dot (CQD) were proposed for determination of His concentration using an approach based on a non-turn-off/turn-on system, but with sensitization of the QD mediated by an AA-metal complexation. ${ }^{31}$

In another hand, few direct AA determinations were developed employing QD as analytical probes. Different carbon dots were employed for determination of essential and non-essential AA in food and biological samples. ${ }^{32,33}$ In a similar way, silicon QD supported on Au nanoparticles was proposed to cysteine determination in serum and urine samples. ${ }^{34}$ However, toxic organic solvent employment, laborious sample pre-treatment and low analytical throughput should be mentioned as drawbacks.

To the best of our knowledge, there are no methods based on direct AA determination using CdTe QD, considering their impact on analytical performance, namely selectivity, sensitivity and analytical productivity. In view of the tripeptide structure and the antioxidant metabolic function of glutathione in humans, ${ }^{35}$ the present study aimed to evaluate the interaction between glutathione-capped CdTe QDs (GSH-CdTe QD) and AAs. Thermodynamic parameters and binding constants were determined, as well as their repercussion on analytical features for the development of fast and simple clinical tests. The findings of the study allowed for the proposition of a method to directly determine His in urine samples, based on the luminescence quenching of GSH-CdTe QDs caused by the presence of the analyte.

\section{Experimental}

\section{Reagents and solutions}

All analytical reagents employed were of analytical grade and their solutions were prepared with ultrapure water with a specific resistivity of $18.2 \mathrm{M} \Omega \mathrm{cm}$ that was obtained from a purification system (Milli-Q, Elga, Purelab Option-Q, Birmingham, United Kingdom). The reagents used in the synthesis of GSH-CdTe QD were: $\mathrm{NaBH}_{4}$ (98\%), $\mathrm{CdCl}_{2} \cdot 5 \mathrm{H}_{2} \mathrm{O}$ (79-81\%), $\mathrm{Na}_{2} \mathrm{TeO}_{3}(99 \%)$, sodium citrate and reduced glutathione, all from Sigma-Aldrich, (Darmstadt, Germany). Ethanol (98\%) and $\mathrm{NaOH}(98 \%)$ were from Moderna (São Paulo, Brazil). $\mathrm{NaCl}, \mathrm{Na}_{2} \mathrm{SO}_{4}$, $\mathrm{KH}_{2} \mathrm{PO}_{4}, \mathrm{KCl}, \mathrm{NH}_{4} \mathrm{Cl}$, urea and creatinine, all purchased from Merck (Darmstadt, Germany), were used to prepare the artificial urine samples. The employed AAs, namely L-alanine (Ala), L-asparagine (Asn), L-glycine (Gly), L-isoleucine (Ile), L-leucine (Leu), L-valine (Val), L-phenylalanine (Phe), L-histidine (His), L-arginine (Arg), L-lysine (Lys), L-threonine (Thr), L-tryptophan (Trp), L-methionine (Met), L-aspartic acid (Asp) and L-glutamic acid (Glu), were from Merck (Darmstadt, Germany). Standard solutions of $\mathrm{Zn}$ and Co $\left(1,000 \mathrm{mg} \mathrm{L}^{-1}\right.$; Specsol, São Paulo, Brazil) were used to evaluate interferents. Buffer solutions were prepared from sodium acetate $\left(0.25 \mathrm{~mol} \mathrm{~L}^{-1}\right.$, pH 4 to 6) and $\mathrm{NH}_{4} \mathrm{Cl}$ (0.1 to $\left.0.8 \mathrm{~mol} \mathrm{~L}^{-1}, \mathrm{pH} 8\right)$, both from Merck (Darmstadt, Germany). Britton-Robinson (BR) buffer was prepared from $\mathrm{H}_{3} \mathrm{BO}_{3}, \mathrm{H}_{3} \mathrm{PO}_{4}$ and acetic acid (0.04 $\mathrm{mol} \mathrm{L}^{-1}, \mathrm{pH} 5$ to 9), all from Merck (Darmstadt, Germany). QD working solutions were prepared daily in a concentration range of 7.5 to $50.0 \mu \mathrm{mol} \mathrm{L}^{-1}$; an appropriate mass was diluted to $20.0 \mathrm{~mL}$ with water. AA stock solutions were prepared at $100 \mathrm{mmol} \mathrm{L}^{-1}$, and working solutions from 0.002 to $35 \mathrm{mmol} \mathrm{L}^{-1}$ were obtained by dilution with water.

\section{Instrumentation}

A UV-Vis molecular absorption spectrophotometer (Varian, Cary 50 Eclipse, Santa Clara, USA) and a 
molecular spectrofluorometer (Varian, Cary Eclipse, Santa Clara, USA), equipped with 1-cm light pathway quartz cell and a Fourier transform infrared (FTIR) spectrometer (PerkinElmer, Spectrum Two, Waltham, USA) were employed for QD characterization and analytical measurements. All $\mathrm{pH}$ measurements were made with an ST3100-F pH meter (Ohaus, Parsippany, USA) equipped with a combined $\mathrm{Ag} / \mathrm{AgCl}$ glass electrode. A centrifuge (Marconi, MA-1810, Piracicaba, Brazil) was utilized for QD purification and separation.

\section{QD synthesis and optical characterization}

GSH-CdTe QD nanocrystals were synthesized using a hydrothermal method, following a previous procedure with minor modifications. ${ }^{36}$ In summary, the GSH-CdTe QD nanocrystals were synthesized weighing $200 \mathrm{mg}$ of $\mathrm{NaBH}_{4}$, $55.4 \mathrm{mg}$ of $\mathrm{Na}_{2} \mathrm{TeO}_{3}, 460 \mathrm{mg}$ of glutathione and $310 \mathrm{mg}$ of sodium citrate, followed by the addition of $120 \mathrm{~mL}$ of $1.9 \mathrm{~g} \mathrm{~L}^{-1} \mathrm{CdCl}_{2}$ under magnetic stirring, with a final molar ratio of Cd:Te:GSH fixed at 5:1:6. The $\mathrm{pH}$ value of the system was adjusted to 10.2 by the addition of $0.1 \mathrm{~mol} \mathrm{~L}^{-1} \mathrm{NaOH}$ solution. The synthesis was placed in a reflux system under magnetic stirring and heated at $100{ }^{\circ} \mathrm{C}$. The QD size was controlled according to different synthesis times, a procedure that allowed for the production of three different sized probes in this experiment. The obtained GSH-CdTe QD solution was purified by precipitation with ethanol. Thereafter, the precipitated suspension was centrifuged $(2,300 \mathrm{RCF}$, relative centrifugal field) for $10 \mathrm{~min}$ at room temperature, and the nanocrystal particles were subsequently vacuum dried.

Optical properties of the QD were obtained from the absorption (recorded from 200 to $800 \mathrm{~nm}$ ) and fluorescence (recorded from 450 to $600 \mathrm{~nm}$, excitation wavelength $\left(\lambda_{\text {exc }}\right)$ at $\left.400 \mathrm{~nm}\right)$ spectra acquired with a $1-\mathrm{cm}$ light pathway quartz cell. The particle size of the synthesized QD was estimated by employing the mathematical model (equation 1) proposed by Yu et al..$^{37}$

$\mathrm{D}=\left(9.8127 \times 10^{-7}\right) \lambda^{3}-\left(1.74147 \times 10^{-3}\right) \lambda^{2}+$

$1.0064 \lambda-194.84$

where $\lambda$ is the wavelength of the first excitonic transition peak and D is the average nanocrystal diameter. Thus, 2.2, 2.8 and $3.0 \mathrm{~nm}$ QDs were obtained with emission wavelengths in the visible region at $528.95 \mathrm{~nm}$ (green), $552.05 \mathrm{~nm}$ (yellow) and $567.05 \mathrm{~nm}$ (orange), respectively.

In order to determine the concentrations of all QD dispersions, the extinction coefficient $(\varepsilon)$ of GSH-CdTe QDs, for a given diameter (D), was calculated according to the following expression (equation 2): ${ }^{37}$ $\varepsilon=3450 \times \Delta \mathrm{E} \times \mathrm{D}^{2.4}$

where $\Delta \mathrm{E}$ is the transition energy expressed in $\mathrm{eV}$; this measure corresponds to the first excitonic transition. Subsequently, the QD molar mass was determined by applying Lambert-Beer's law. For all the characterization measurements that were performed, QD dispersion concentrations were kept below $0.01 \mathrm{~mol} \mathrm{~L}^{-1}$.

\section{Procedures}

\section{AA-QD direct interaction evaluation}

The interactions between GSH-CdTe QD and essential AAs were evaluated according to their side chain characteristics. There were three study groups: (i) Iso, Leu and Val (apolar), (ii) His and Arg (basic) and (iii) Thr and Trp (polar neutral). For the evaluation of the interaction between AA and GSH-CdTe QD, stock solutions of 2.2, 2.8 and $3.0 \mathrm{~nm}$ QD (based on initial emission intensity) were prepared daily, at concentrations of 50.0, 7.4 and $8.6 \mu \mathrm{mol} \mathrm{L}{ }^{-1}$, respectively. Subsequently, $1.0 \mathrm{~mL} \mathrm{AA}$ aliquots were added to $1.0 \mathrm{~mL}$ of each fluorescence probe dispersion, and the emission spectra were recorded from 450 to $600 \mathrm{~nm}\left(\lambda_{\text {exc }}=400 \mathrm{~nm}\right)$. The final concentration of AA test solution ranged from 2.0 to $333 \mu \mathrm{mol} \mathrm{L}^{-1}$.

Complementary assays with apolar AAs were carried out for charge effect evaluation under different acidity conditions. To ensure suitable sensibility, stock solutions at $1.0 \mathrm{mmol} \mathrm{L}^{-1}$ were employed. Then, experiments were performed by adding an aliquot of $\mathrm{AA}(2.0 \mathrm{~mL})$ to the luminescent probe, which was composed of $1.0 \mathrm{~mL}$ of QD $\left(2.2 \mathrm{~nm}, 50.0 \mu \mathrm{mol} \mathrm{L}^{-1}\right)$ and $1.0 \mathrm{~mL}$ of acetate buffer $\left(0.25 \mathrm{~mol} \mathrm{~L}^{-1}\right)$ at $\mathrm{pH} 4.5$ to 6 .

\section{Method optimization and validation}

The method to determine the selected AA, His, was optimized according to a univariate model that used the fluorescence intensity variation $(\Delta \mathrm{F})$ as an analytical response (equation 3):

$\Delta \mathrm{F}=\left(\mathrm{I}_{0}-\mathrm{I}\right) / \mathrm{I}_{0} \times 100$

where $\mathrm{I}_{0}$ and $\mathrm{I}$ are the QD emission intensity in the absence and presence, respectively, of the analyte.

Parameters, such as QD concentration, $\mathrm{pH}$, buffer composition and concentration, were evaluated. For the evaluation of QD concentration, working solutions were prepared in the range 2.5 to $30.0 \mu \mathrm{mol} \mathrm{L} \mathrm{L}^{-1}$. Specifically, a QD aliquot $(1.0 \mathrm{~mL})$ was analyzed in the presence of the buffer solution $(1.0 \mathrm{~mL})$ and the analyte $\left(20 \mathrm{mmol} \mathrm{L}^{-1}\right)$. Similarly, the $\mathrm{pH}$ value was optimized from 5.0 to 9.0 
using BR buffer $\left(0.04 \mathrm{~mol} \mathrm{~L}^{-1}\right)$. The composition effect of the buffer solution was also evaluated by comparison of the phosphate and ammoniacal buffers at the same concentration. Finally, the buffer concentration was studied in the range of 0.04 to $0.8 \mathrm{~mol} \mathrm{~L}^{-1}$.

Potential interferents were evaluated by adding the investigated species to AA/QD solutions. The tests were performed by adding $100 \mu \mathrm{L}$ of potential interferent stock solutions on the fluorescent probe at optimum conditions. Final volume was made up to $1.0 \mathrm{~mL}$, leading to an interfering test domain ranging from 0.00023 to $0.185 \mathrm{mmol} \mathrm{L}^{-1}$ in presence of $20 \mathrm{mmol} \mathrm{L}^{-1}$ histidine. The ratio between QD signal in presence of His $\left(\mathrm{F}_{0}\right)$ and His/interferent solutions (F) was taken as analytical response. The reference ratio was obtained by independently QD/His solutions recorded in two triplicate sets (before and after interferent measurements) to bias evaluation.

The matrix effect was studied by evaluating parallelism between the calibration curves in solvent and fortified urine samples. The limit of detection (LOD) and the limit of quantification (LOQ) were calculated from the means of the equations $3.3 \mathrm{sb} / \mathrm{S}$ and $10 \mathrm{sb} / \mathrm{S}$, respectively, where $\mathrm{sb}$ is the residual standard deviation of the regression line and $\mathrm{S}$ is the slope of the calibration curve. ${ }^{38}$

\section{Quenching mechanism study}

The quenching mechanism was investigated by evaluating the temperature effect. The assays were performed by adding suitable volumes of the His stock solution to the probe, composed of $0.25 \mathrm{~mL}$ of QD $\left(2.2 \mathrm{~nm}, 20.0 \mu \mathrm{mol} \mathrm{L}^{-1}\right)$ and $0.25 \mathrm{~mL}$ of ammoniacal buffer $\left(0.25 \mathrm{~mol} \mathrm{~L}^{-1}, \mathrm{pH} 8.0\right)$, with the volume adjusted to $1.0 \mathrm{~mL}$ to achieve final AA concentrations that ranged from 5.0 to $35.0 \mathrm{mmol} \mathrm{L}^{-1}$. These probe test solutions were performed at 293,300 and $308 \mathrm{~K}$, and their emission spectra were recorded from 450 to $600 \mathrm{~nm}\left(\lambda_{\text {exc }}=400 \mathrm{~nm}\right)$. The ionic strength effect was evaluated by adding $\mathrm{NaCl}$ solutions $(0.1$ to $0.3 \mathrm{~mol} \mathrm{~L}^{-1}$ ) to the probe test solution described above.

\section{Sample analysis}

Artificial urine was adopted as a model sample to simulate AA determination in clinical tests because this sample is widely used to simulate biological fluid for in vitro studies in urinalysis diagnosis assays. ${ }^{39}$ Artificial urine was prepared according to Laube et al. ${ }^{40}$ specifically by employing inorganic and organic mimetic constituents: $\mathrm{CaCl}_{2} \cdot 2 \mathrm{H}_{2} \mathrm{O}, \mathrm{NaCl}, \mathrm{Na}_{2} \mathrm{SO}_{4}, \mathrm{KH}_{2} \mathrm{PO}_{4}, \mathrm{KCl}, \mathrm{NH}_{4} \mathrm{Cl}$, urea and creatinine. Human urine samples were collected from healthy adult volunteers according to the Ethics Committee guidelines (protocol number 20335919.5.0000.8035).
These samples were frozen at $-4{ }^{\circ} \mathrm{C}$ from the time of collection to analysis. The pretreatment step of the samples consisted of centrifuging them at 2,300 RCF for 10 min to remove particulate material. AAs were spiked at three concentration levels 3.0, 6.0 and $12.0 \mathrm{~g} \mathrm{~L}^{-1}$ (or 5.0, 10.0 and $20 \mathrm{mmol} \mathrm{L}^{-1}$, respectively, final concentration) to resemble aminoacidopathic conditions. Sample analyses were performed with the addition of $250 \mu \mathrm{L}$ of a urine sample (without any further pre-treatment) to QD probes under optimum conditions $\left(250 \mu \mathrm{L}\right.$ of $20.0 \mu \mathrm{mol} \mathrm{L}^{-1}$ $2.2 \mathrm{~nm}$ GSH-CdTe QD dispersion buffered at $\mathrm{pH}$ 8.0). The fluorescence signal was recorded at the maximum emission wavelength.

\section{Results and Discussion}

\section{Evaluation of the interaction between the AAs and QDs}

Firstly, to confirm that the synthesized QD were GSH-capped, FTIR spectra of GSH and GSH-CdTe (Figure 1a) were compared. In the GSH spectrum, it is possible to observe characteristic bands of the group $-\mathrm{COOH}$ around 1712-1601 $\mathrm{cm}^{-1}$ (symmetric $v \mathrm{COO}-$ ), $1396 \mathrm{~cm}^{-1}$ (asymmetric $\left.v \mathrm{COO}-\right), 1712 \mathrm{~cm}^{-1}(v \mathrm{C}=\mathrm{O})$ and $1280 \mathrm{~cm}^{-1}(\delta \mathrm{OH})$. The groups $-\mathrm{NH}_{2}$ and $-\mathrm{SH}$ are indicated with bands around 3344-3028 $\mathrm{cm}^{-1}$ (symmetric $v \mathrm{~N}-\mathrm{H}$ ) and $2522 \mathrm{~cm}^{-1}$ (symmetric $v \mathrm{~S}-\mathrm{H}$ ), respectively. In the spectrum corresponding to synthesized GSH-CdTe, it is possible to observe that the sharp band at $1396 \mathrm{~cm}^{-1}$ is from the bending vibration of $\mathrm{C}-\mathrm{NH}$, and the band at $1585 \mathrm{~cm}^{-1}$ corresponding to the asymmetric stretching vibrations of the carboxylate anions. The disappearance of $\mathrm{S}-\mathrm{H}$ group vibration $2522 \mathrm{~cm}^{-1}$ (symmetric $v \mathrm{~S}-\mathrm{H}$ ) is an indicative of a covalent bond stablished between $\mathrm{Cd}$ and GSH. ${ }^{41-43}$

Moreover, absorption and photoluminescent spectral analyses were performed for the different synthesized GSH-CdTe nanocrystals. All fluorescence spectra have shown symmetric and narrow profiles with full width at half maximum (FWHM) below $56 \mathrm{~nm}$. Based on first excitonic transitions on the absorption spectra, nanoparticle average diameters of 2.2, 2.8 and $3.0 \mathrm{~nm}$ were estimated, with maximum emission wavelengths equal to 529,552 and $567 \mathrm{~nm}$, respectively (Figure 1b). The QD size results were in agreement with previous reports ${ }^{44,45}$ for thiol capped CdTe QD produced by hydrothermal route, which also proved minor deviations between mathematical model and transmission electron microscopy characterizations.

AAs in aqueous media can occur in three different forms: cationic ( $\mathrm{pH}<\mathrm{pI}$, isoelectric point), zwitterionic $(\mathrm{pH}=\mathrm{pI}$, positively and negatively charged, the total charge is zero) and anionic ( $\mathrm{pH}>\mathrm{pI})$. Thus, the initial tests 

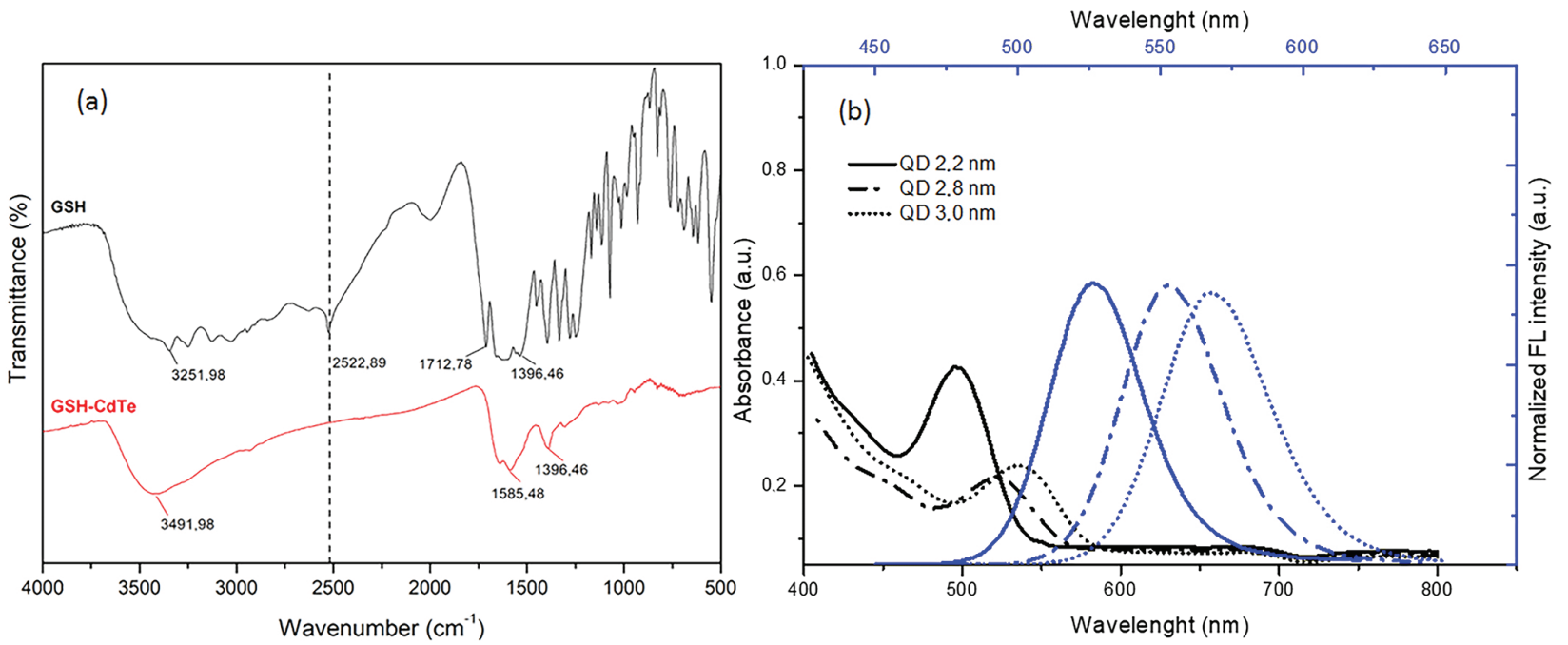

Figure 1. (a) FTIR spectra of GSH and GSH-CdTe quantum dots, and (b) UV-Vis absorption and FL spectra of GSH-CdTe QDs with different diameters.

were performed in aqueous medium without $\mathrm{pH}$ buffering (pH ca. 6.0). AAs with apolar side chains, Iso (pI 6.0), Leu (pI 6.0) and Val (pI 6.0), did not show a significant interaction with the synthesized QDs; the signal variation was less than 5\% within the evaluated range. The same behavior was observed for AAs with neutral polar side chains (non-charged); none of them showed an interaction with the tested GSH-CdTe QDs (2.2, 2.8 and $3.0 \mathrm{~nm}$ ), with the exception of Thr (pI 5.60). In the presence of Thr $\left(80.0 \mu \mathrm{mol} \mathrm{L}^{-1}\right)$, GSH-CdTe QDs $(2.8 \mathrm{~nm})$ showed a decay of 23\% (Figure 2a), reaching total suppression at Thr concentrations above $250.0 \mu \mathrm{mol} \mathrm{L} \mathrm{L}^{-1}$ (Figure 2b).

Basic side chain AAs (positively charged) were evaluated similarly to the non-polar and polar side chain AA experiments. Arg (pI 10.8) showed no significant interaction with any QD sizes $(\Delta \mathrm{F}=-9 \%)$; indeed, the majority of Arg was in cationic form in aqueous medium. On the other hand, His ( $\mathrm{pI}$ 7.6) showed no interference in the emission profile of 2.8 and $3.0 \mathrm{~nm}$ QD, but there was a sharp decrease in the emission of $2.2 \mathrm{~nm}$ QDs at concentrations above $80.0 \mu \mathrm{mol} \mathrm{L}^{-1}(\Delta \mathrm{F}=75 \%$; Figure 2a).

There was an effective interaction between His and $2.2 \mathrm{~nm}$ QD due to the presence of an imidazole group in its side chain, as reported in previous investigations ${ }^{46}$ in which direct interaction between imidazolic compounds and QD was also observed. Given that the $\mathrm{pH}$ value was approximately equal to the $\mathrm{pI}$ value of His, the total charge is zero because it is in the zwitterionic form, i.e., the amino group is positively charged, and the carboxylic group is negatively charged. These phenomena might lead to an interaction with the QD surface ligand due to hydrogen bonding or van der Waals forces. ${ }^{47}$ Furthermore, the
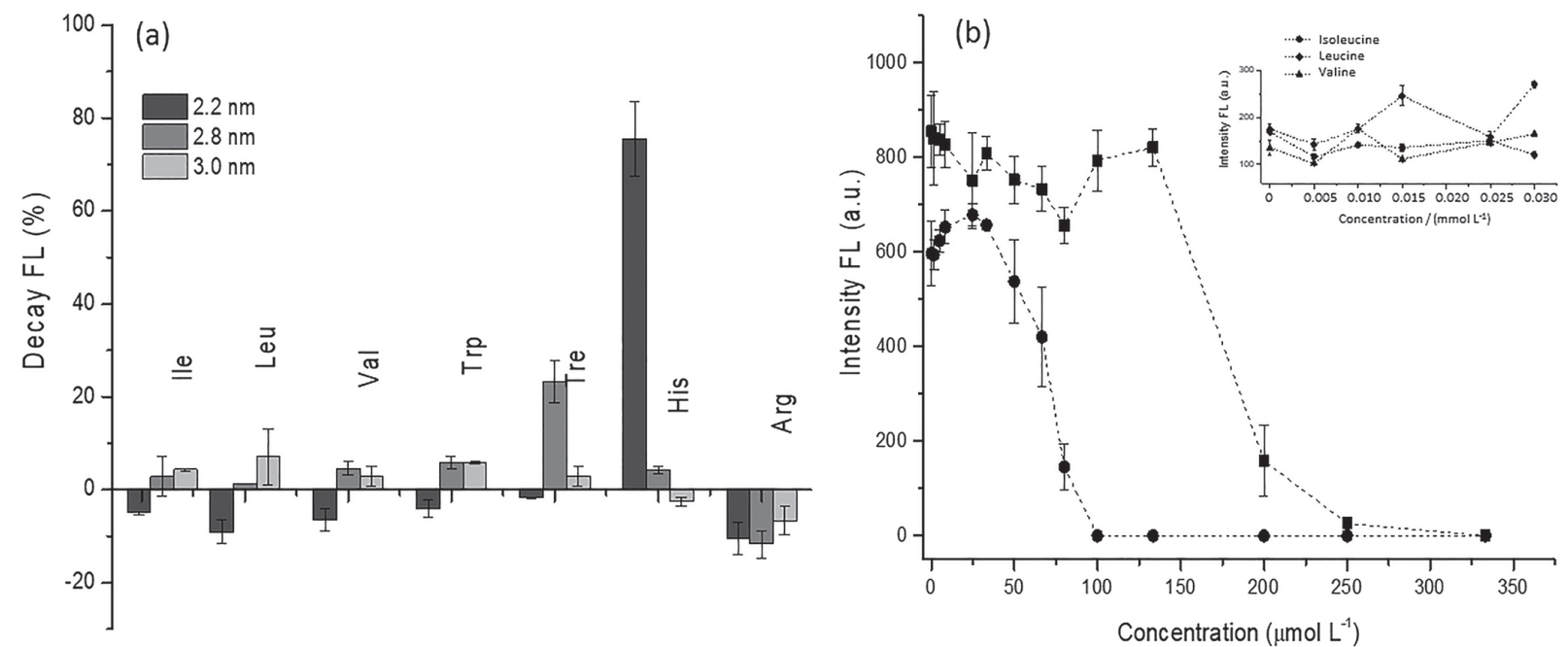

Figure 2. (a) Evaluation of interaction between GSH-CdTe QD (2.2, 2.8 and $3.0 \mathrm{~nm}$ ) and the amino acids Iso, Leu, Val, Thr, Met, His, Arg and Trp $\left(80 \mu \mathrm{mol} \mathrm{L}^{-1}\right)$, (b) interaction between GSH-CdTe QD and His $(\bullet)$ and Thr ( $\bullet$ ) (1.6 to $\left.333 \mu \mathrm{mol} \mathrm{L}^{-1}\right)$, and interaction between GSH (2.2 nm), and apolar amino acids at $\mathrm{pH} 4.5$ (5.0 to $30 \mathrm{mmol} \mathrm{L}^{-1}$ ) (inset graphic). 
previously mentioned QD-size-dependent interactions, in which preferential sensing by smaller nanocrystals occurs due to a higher surface/volume ratio, were observed. ${ }^{48}$

In order to evaluate the interaction model, assays in acidic media were performed to protonate the basic sites of the AA side chains (Iso, Leu and Val, all of which have a pI value around 6.0). Notably, these AAs did not interact with the evaluated QDs in previous experiments. The evaluated $\mathrm{pH}$ range (4.5 to 6.0 ) was chosen considering that, at a lower $\mathrm{pH}$, there is a decrease in quantum efficiency due to protonation of thiol carboxyl groups. The presence of AA apolar side chains caused a significant decay in the $2.2 \mathrm{~nm}$ QD emission (ranging from 5 to $25 \%$ ) at $\mathrm{pH} 4.5$ and 5.0, but there was no significant interaction at $\mathrm{pH}$ 6.0. This behavior can be explained by the fact that at a pH lower than the AA pI value, the cationic form prevails, a phenomenon that denotes a charge availability effect on direct AA-QD interactions and sensing selectivity. The last results of His and apolar AA in acidy medium indicated that AA sensing by QD demands charged groups or specific molecules moieties. It is important to note that although apolar AAs can be a quencher due to $\mathrm{pH}$ control and charge distribution modification, poor linearity and sensitivity were observed (Figure 2b, inset) hindering the analytical method development.

Method optimization and interaction mechanism between GSH-CdTe QD and His

Since the interaction between His and GSH-CdTe QD demonstrated stronger fluorescence suppression, repeatability and linear correlation, a direct method for the determination of this AA was proposed, employing artificial

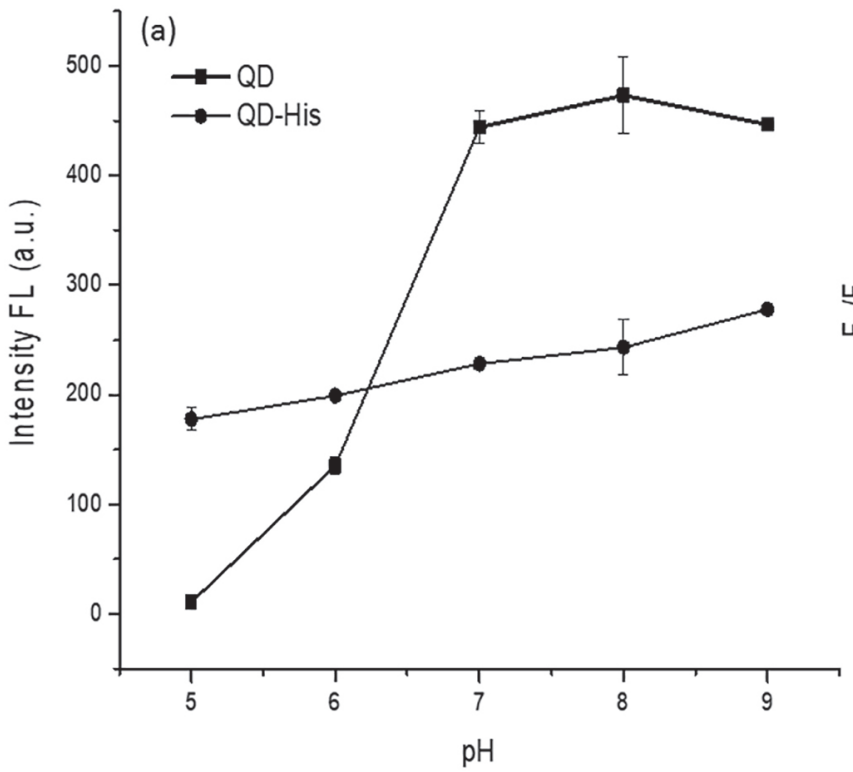

urine as a model sample to simulate a clinical analysis. In this way, the luminescent probe composition was studied to ensure greater sensitivity and selectivity.

First, there was a decrease in QD quantum efficiency at $\mathrm{pH}$ values close to 5 when compared to alkaline conditions since the QD interaction sites are protonated in more acidic media, a phenomenon that reduces the fluorophore population by precipitation. ${ }^{49}$ However, in the presence of His, the emission signal was enhanced, instead of quenched, at $\mathrm{pH}$ 5. This effect might be due to proton competition between His and cap molecules on QDs. For $\mathrm{pH}$ values above 7, there were no significant changes in the emission signal of the His-QD system, with a maximum quenching emission at $\mathrm{pH} 8(\Delta \mathrm{F}=42 \%)$. Nevertheless, the $\mathrm{pH}$ change did not significantly affect the His-QD interaction (poor signal variation), as can be seen in Figure 3a. It is important to notice that for almost the full $\mathrm{pH}$ range evaluated, the histidine dominant form did not change, ${ }^{50}$ explaining the negligible $\mathrm{pH}$ effect observed. His is a zwitterion within pH 6 to 9 with imidazole group in its neutral form. This behavior also suggests the imidazole group actuation, as well as the possible van der Waals forces and hydrogen bonding model. Hence, the achieved sensitivity gain occurred due to the intensification of QD emissions associated with neutralization of the glutathione acid group.

Given that the medium composition can influence the luminescent probe performance, the buffer type was investigated. Ammoniacal buffer solution provided the maximum emission decay, and when this solution was evaluated in the range of 0.04 to $0.8 \mathrm{~mol} \mathrm{~L}^{-1}$, there was no significant difference in the QD emission suppression in the presence of L-His. Therefore, a $0.25 \mathrm{~mol} \mathrm{~L}^{-1}$ ammoniacal

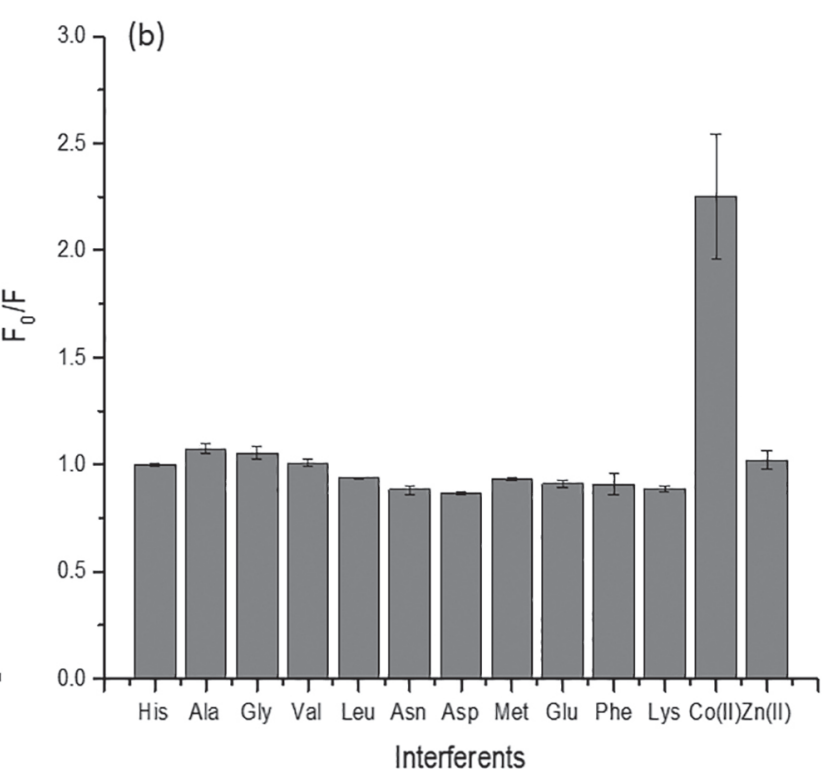

Figure 3. (a) Evaluation of the $\mathrm{pH}$ effect on GSH-CdTe QD-His system $\left(\mathrm{C}_{\mathrm{His}}=20 \mathrm{mmol} \mathrm{L}^{-1}\right)$, and (b) interference study $\left(\mathrm{C}_{\mathrm{QD}}=20 \mu \mathrm{mol} \mathrm{L}^{-1} ; \mathrm{C}_{\mathrm{His}}=20 \mathrm{mmol} \mathrm{L}^{-1}\right)$. 
buffer solution was chosen to maintain the $\mathrm{pH}$ value at 8.0 without compromising sensitivity. The QD concentration was also evaluated in the concentration range of 2.5 to $30 \mu \mathrm{mol} \mathrm{L}{ }^{-1}$; the $20 \mu \mathrm{mol} \mathrm{L}{ }^{-1}$ solution presented a higher percentage of decay $(\Delta \mathrm{F}=32 \%)$ and better precision, being a fixed recommended condition, as shown in previous studies. ${ }^{51}$

Under optimum conditions, the quenching mechanisms, interaction magnitude and associated thermodynamic parameters were evaluated by examining the temperature effect. The surface phenomena that lead to quenching of the QD emission signal can be characterized as dynamic, static or a combination of static and dynamic, in which case, the Stern-Volmer plot is characterized by a nonlinear relationship and represented by the polynomial (equation 4):

$$
\frac{\mathrm{F}_{0}}{\mathrm{~F}}=1+\left(\mathrm{K}_{\mathrm{D}}+\mathrm{K}_{\mathrm{S}}\right)[\mathrm{Q}]+\mathrm{K}_{\mathrm{D}} \mathrm{K}_{\mathrm{s}}[\mathrm{Q}]^{2}
$$

where $\mathrm{F}_{0}$ and $\mathrm{F}$ are the fluorescence intensities of QD in
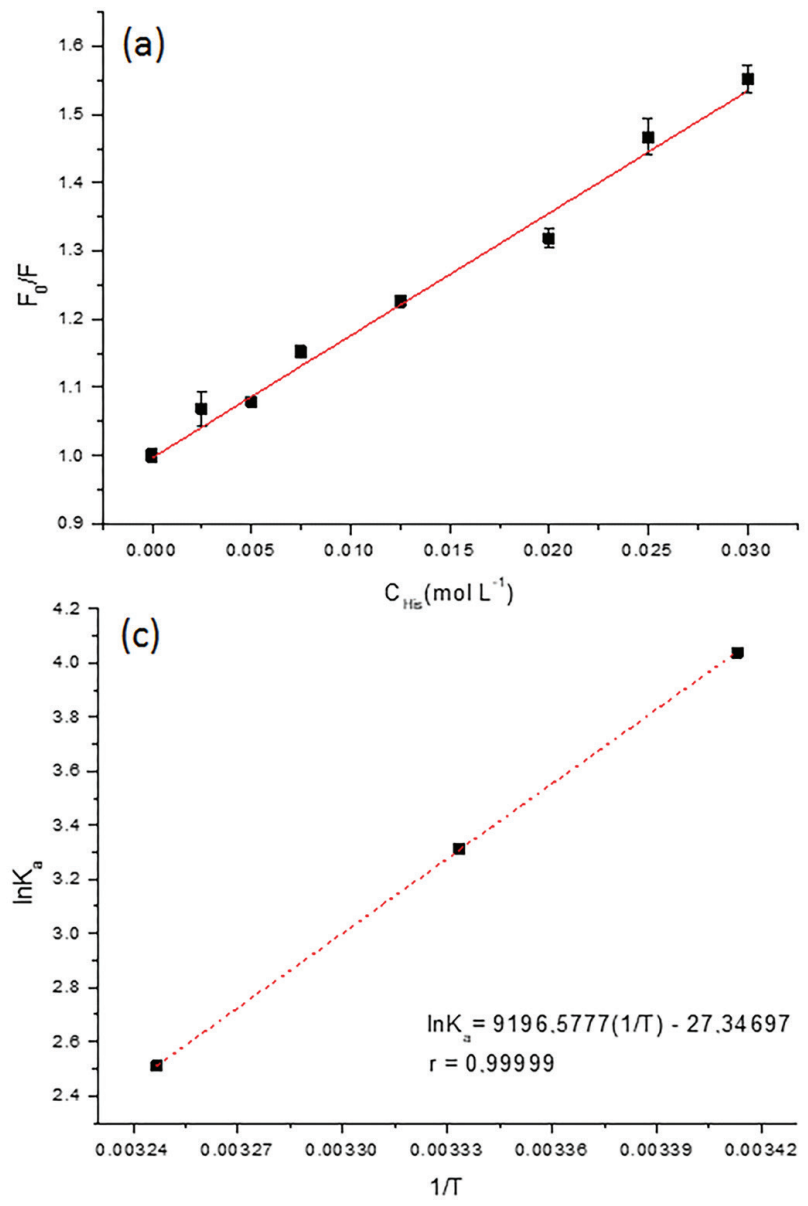

the absence and presence, respectively, of the quencher, $\mathrm{K}_{\mathrm{D}}$ and $\mathrm{K}_{\mathrm{S}}$ are the dynamic and static quenching constants, respectively, and $[\mathrm{Q}]$ is the molar concentration of the quencher, in this case His. The Stern-Volmer equation determined for the His-QD interaction was (equation 5):

$$
\begin{aligned}
& \mathrm{F}_{0} / \mathrm{F}=(0.9967 \pm 0.0086)+(17.93 \pm 0.87) \times[\mathrm{His}] \\
& (\mathrm{r}=0.9930, \text { correlation coefficient })
\end{aligned}
$$

According to Figure 4a, the Stern-Volmer plot showed linear behavior. This finding demonstrated that the quenching mechanism between GSH-CdTe QDs and His is not due to a combination of dynamic and static quenching. ${ }^{52}$

The mechanism for the His-GSH-CdTe QD system based on Stern-Volmer curves was evaluated at three different temperatures (Figure $4 \mathrm{~b}$ ). The constant $\mathrm{K}_{\mathrm{sv}}$ (quenching constant), which defines [Q], was calculated according to equation 6 and is presented in Table 1 .

$$
\frac{\mathrm{F}_{0}}{\mathrm{~F}}=1+\mathrm{K}_{\mathrm{sv}}[\mathrm{Q}]
$$
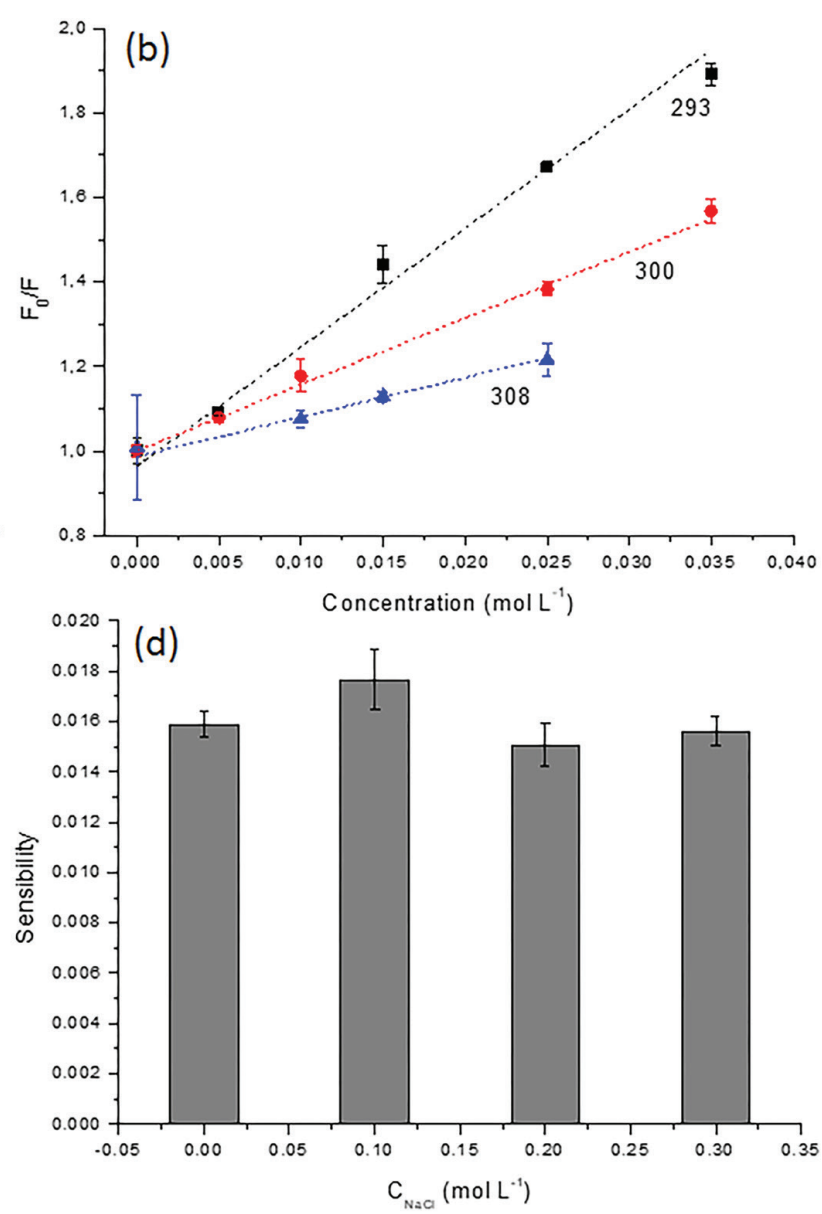

Figure 4. (a) Stern-Volmer plot, (b) Stern-Volmer curves for GSH-CdTe QD in presence of His at three different temperatures: 293 , 300 and $308 \mathrm{~K}$ $\left(\mathrm{C}_{\mathrm{QD}}=20 \mu \mathrm{mol} \mathrm{L}{ }^{-1} ; \mathrm{C}_{\mathrm{His}}\right.$ varying from 0 to $\left.0.35 \mathrm{~mol} \mathrm{~L}^{-1} ; \mathrm{pH} 8.0\right)$, (c) van't Hoff plot, and (d) ionic strength evaluation for QD-His system ( $\mathrm{C}_{\mathrm{NaCl}}$ varying from 0.1 to $0.3 \mathrm{~mol} \mathrm{~L}^{-1}$ ). 
Hence, it was observed that $\mathrm{K}_{\mathrm{sv}}$ decreased as a function of the increase in temperature. These data indicate that the quenching process between GSH-CdTe QDs and His was static. $^{53-55}$

The fluorescence quenching of GSH-CdTe QDs by His can be characterized by a modified Stern-Volmer equation, which is usually employed to treat a static quenching mechanism (equation 7):

$\frac{\mathrm{F}_{0}}{\left(\mathrm{~F}_{0}-\mathrm{F}\right)}=\frac{1}{\mathrm{f}_{\mathrm{a}} \mathrm{K}_{\mathrm{a}}} \frac{1}{[\mathrm{Q}]}+\frac{1}{\mathrm{f}_{\mathrm{a}}}$

where $\mathrm{K}_{\mathrm{a}}$ is the effective quenching constant for accessible fluorophores or association constant, and $\mathrm{f}_{\mathrm{a}}$ is the fraction of accessible fluorophores. The decreasing trend of $K_{a}$ values with increasing temperature, as observed in Table 1 , corroborates the behavior observed for $\mathrm{K}_{\mathrm{sv}}$ values. This finding indicates that the His-QD binding was moderate and the complex formed is reversible. ${ }^{56}$

The predominant force type of the His-QD interaction can be obtained by calculating the thermodynamic parameters, enthalpy $(\Delta \mathrm{H})$ and entropy $(\Delta \mathrm{S})$, both of which were obtained by the van't Hoff equation (equation 8) (Figure $4 \mathrm{c}){ }^{57}$ These parameters were used to obtain the Gibbs free energy ( $\Delta \mathrm{G}$; equation 9) (Table 1$)$ :

$\ln \mathrm{K}_{\mathrm{a}}=-\frac{\Delta \mathrm{H}}{\mathrm{R}} \frac{1}{\mathrm{~T}}+\frac{\Delta \mathrm{S}}{\mathrm{R}}$

$\Delta \mathrm{G}=\Delta \mathrm{H}-\mathrm{T} \Delta \mathrm{S}$

where $\mathrm{K}_{\mathrm{a}}$ is the association constant for each temperature ( $\mathrm{T}$ ) and $\mathrm{R}$ is the universal gas constant. The values of $\Delta \mathrm{H}=-76.5 \mathrm{~kJ} \mathrm{~mol}^{-1}$ and $\Delta \mathrm{S}=-227.4 \mathrm{~J} \mathrm{~K}^{-1} \mathrm{~mol}^{-1}$ demonstrated that the enthalpic factor is more influential than the entropic factor. The values of $\Delta \mathrm{H}<0$ and $\Delta \mathrm{S}<0$ indicated that the His-QD complex formation occurred by an exothermic process associated with Van der Waals force and hydrogen bond interactions. ${ }^{58}$ The values of $\Delta \mathrm{G}<0$ demonstrated that the His-QD complexation occurs through a spontaneous process. ${ }^{59}$
In order to ratify the type of interaction observed between His and QD, a study was performed regarding the ionic strength influence by the addition of $\mathrm{NaCl}$ at different concentrations ( 0.1 to $\left.0.3 \mathrm{~mol} \mathrm{~L}^{-1}\right)$ (Figure $4 \mathrm{~d}$ ). This influence on the QD and AA interaction can be evaluated due to the fact that when the interaction is of an electrostatic type, the analytical sensitivity decreases with the elevated salt concentration. In this study, the analytical sensitivity did not present a significant difference in the absence and presence of $\mathrm{NaCl}$. This behavior is related to the fact that the interaction between the QD and His has a preference for Van der Waals forces and hydrogen bonding rather than electrostatic interactions. ${ }^{60}$ To estimate the interaction site between His and QD, the binding constant $\mathrm{K}_{\mathrm{b}}$ was obtained for the three temperatures using equation 10 :

$\log \left[\frac{\mathrm{F}_{0}-\mathrm{F}}{\mathrm{F}_{\mathrm{o}}}\right]=\mathrm{K}_{\mathrm{b}}+n \log [\mathrm{Q}]$

where $n$ is the number of binding sites and [Q] is the molar concentration of His. From the mathematical model, it was verified that $\mathrm{K}_{\mathrm{b}}$ presented behavior similar to $\mathrm{K}_{\mathrm{sv}}$, with the magnitude decreasing with increasing temperature. This result suggested that static quenching was associated with the formation of a His-QD complex without fluorescence at the ground state. As expected for exothermic processes, higher temperatures impair the extent of a reaction and lead to smaller constant values. ${ }^{61}$ Finally, from the same mathematical model, the number of binding sites between His and the QD was predicted to be approximately one. This finding implies the existence of only one interaction site between His and QD. All these data are presented in Table 1.

These thermodynamic findings are in accordance with system behavior observed on preliminary interaction studies and $\mathrm{pH}$ optimization, as well as few reports ${ }^{62,63}$ that confirm the possibility of hydrogen bonds between neutral imidazole groups with different substrates.

Table 1. Stern-Volmer parameters $\left(\mathrm{K}_{\mathrm{sv}}\right)$, association constant $\left(\mathrm{K}_{\mathrm{a}}\right)$, binding parameters $\left(\mathrm{K}_{\mathrm{b}}\right)$ and thermodynamic parameters for the GSH-CdTe-His system at different temperatures

\begin{tabular}{|c|c|c|c|c|c|c|c|c|c|}
\hline \multirow{2}{*}{$\begin{array}{l}\text { Temperature / } \\
\mathrm{K}\end{array}$} & \multirow{2}{*}{$\begin{array}{c}\mathrm{K}_{\mathrm{sv}} / \\
\left(10 \mathrm{~L} \mathrm{~mol}^{-1}\right)\end{array}$} & \multirow[b]{2}{*}{$r$} & \multirow{2}{*}{$\begin{array}{c}\mathrm{K}_{\mathrm{a}} / \\
\left(10 \mathrm{~mol} \mathrm{~L}^{-1}\right)\end{array}$} & \multirow{2}{*}{$\begin{array}{c}\mathrm{K}_{\mathrm{b}} / \\
\left(10^{-2} \mathrm{~mol} \mathrm{~L}^{-1}\right)\end{array}$} & \multirow[b]{2}{*}{$n$} & \multirow[b]{2}{*}{$\mathrm{r}$} & \multicolumn{3}{|c|}{ Thermodynamic parameters } \\
\hline & & & & & & & $\begin{array}{c}\Delta \mathrm{G} / \\
\left(\mathrm{kJ} \mathrm{mol}{ }^{-1} \mathrm{~K}\right)\end{array}$ & $\begin{array}{c}\Delta \mathrm{H} / \\
\left(\mathrm{kJ} \mathrm{mol}^{-1} \mathrm{~K}\right)\end{array}$ & $\begin{array}{c}\Delta \mathrm{S} / \\
\left(\mathrm{J} \mathrm{mol}^{-1}\right)\end{array}$ \\
\hline 293 & 2.81 & 0.99825 & $5.7 \pm 0.09$ & $4.23 \pm 0.18$ & $0.86 \pm 0.12$ & 0.96888 & -9.8 & & \\
\hline 300 & 1.57 & 0.99922 & $2.5 \pm 0.09$ & $2.10 \pm 0.17$ & $0.90 \pm 0.12$ & 0.98216 & -8.3 & -76.5 & -227.4 \\
\hline 308 & 0.94 & 0.99572 & $1.3 \pm 0.19$ & $1.50 \pm 0.19$ & $1.01 \pm 0.15$ & 0.9761 & -6.4 & & \\
\hline
\end{tabular}

$\Delta \mathrm{G}$ : Gibbs free energy; $\Delta \mathrm{H}$ : enthalpy; $\Delta \mathrm{S}$ : entropy; $n$ : number of binding sites; r: correlation coefficient; His: histidine. 


\section{Validation and sample analysis}

The matrix effect was evaluated by the impact of the matrix on the analytical methodology through the parallelism test between calibration curves obtained in aqueous media and the fortified sample. ${ }^{38}$ The parallelism test was evaluated according to regression analysis of the calibration curves and the null hypothesis that both equations are parallel $\left(\mathrm{H}_{0}: \beta_{3}=0\right.$, where $\beta_{3}$ is a regression coefficient corresponding to the difference in slope, parallelism). The $p$-value found from the aqueous and matrix sample curves was 0.57 (higher than $\alpha=0.05$ ), and the null hypothesis was accepted. Thus, the standards were prepared in aqueous media in order to construct the calibration curves for the determination of His in urine samples, as well as confirm preferential interaction with His in presence of different organic compounds.

Under the recommended conditions, the proposed method presented a working linear range with maximum limit at $35 \mathrm{mmol} \mathrm{L}^{-1}$ (with a correlation coefficient (r) of 0.9970 , $\mathrm{n}=7$ ). LOD and LOQ were determined to be $1.6 \times 10^{-4}$ and $4.2 \times 10^{-4} \mathrm{~mol} \mathrm{~L}^{-1}$, respectively. The method showed good precision, with relative standard deviations (RSD) less than $2.5 \%$ (for 2.5 and $20 \mathrm{mmol} \mathrm{L}^{-1} ; \mathrm{n}=6$ ). A comparison of
LOD values and linear range of work with other studies that used QD as luminescent probes is presented in Table 2.

Although this study presented a greater LOD than previous works, in the proposed method, it was not necessary to use an intermediate species. This outcome implies that the proposed method represents a simple analytical approach that consumes less reagent and generates less effluent. In addition, indirect determination, based on turn-off/turn-on by complexation of a metal with $\mathrm{AA}$, is subject to severe interferences from any other ligands present in the sample matrix due the less specificity of the interaction with QD. The species investigated as potential interferents did not present significant changes in the emission signal of the His-QD system $(\Delta \mathrm{F} \pm 5 \%)$, except for $\mathrm{Co}^{\mathrm{II}}$, which presented a $\Delta \mathrm{F}=58 \%$ (Figure $3 \mathrm{~b}$ ). However, the typical $\mathrm{Co}^{\mathrm{II}}$ content present in biological samples is very small, and thus offers no interference to the determination of His in possible clinical tests. ${ }^{68}$ The interferent limiting concentrations are shown in Table 3.

Additional tests that employed three concentrations of artificial urine samples achieved recoveries between 81.5 and $124.3 \%$, and the human urine samples achieved recoveries between 78.7 and $127.6 \%$ (Table 4). These values are in accordance with acceptable recovery values

Table 2. Comparison of the characteristics between the proposed method and reported methods in literature for His determination by carbon quantum $\operatorname{dot}(\mathrm{CQD})$

\begin{tabular}{|c|c|c|c|c|}
\hline Method & Sample & Dynamic range / $\left(\mathrm{mol} \mathrm{L}^{-1}\right)$ & $\mathrm{LOD} /\left(\mathrm{mol} \mathrm{L}^{-1}\right)$ & Reference \\
\hline $\mathrm{Cu}-\mathrm{CQD}$ & biological fluid & $1 \times 10^{-7}-15 \times 10^{-6}$ & $3 \times 10^{-8}$ & 31 \\
\hline GSH-CdTe-Mn ${ }^{\mathrm{II}}$ & synthetic sample & $3.8 \times 10^{-8}-3.0 \times 10^{-3}$ & $1.17 \times 10^{-11}$ & 64 \\
\hline CQD-HgII & human serum & $5 \times 10^{-7}-60 \times 10^{-6}$ & $1.5 \times 10^{-7}$ & 65 \\
\hline $\mathrm{ZnSe}-\mathrm{H}_{2} \mathrm{O}_{2}$ & human serum & $5 \times 10^{-8}-50 \times 10^{-6}$ & $1 \times 10^{-7}$ & 66 \\
\hline DNA-Ag NCs & human urine & $2 \times 10^{-7}-80 \times 10^{-6}$ & $4.3 \times 10^{-9}$ & 67 \\
\hline $\mathrm{Ni}^{\mathrm{II}}-\mathrm{Hcy}-\mathrm{CdTe}$ & human urine & $1 \times 10^{-6}-30 \times 10^{-6}$ & $3 \times 10^{-7}$ & 30 \\
\hline GSH-CdTe & artificial urine & $4.2 \times 10^{-4}-35 \times 10^{-3}$ & $1.6 \times 10^{-4}$ & this work \\
\hline
\end{tabular}

LOD: limit of detection; His: histidine; GSH: glutathione; NCs: nanocrystals; Hcy: homocysteine.

Table 3. Fluorescence variation $(\Delta \mathrm{F})$ of GSH-CdTe-His system in the presence of interferes (His concentration of $20 \mathrm{mmol} \mathrm{L}^{-1}$ )

\begin{tabular}{lccc}
\hline Potential interferent & Tolerance / $\left(\mathrm{mmol} \mathrm{L}^{-1}\right)$ & Ratio analyte / interferent & $\Delta \mathrm{F} / \%$ \\
\hline Alanine & 0.185 & 108 & 4.3 \\
Glycine & 0.104 & 192 & 2.7 \\
Valine & 0.023 & 870 & -1.4 \\
Leucina & 0.045 & 444 & -3.9 \\
Asparagine & 0.040 & 500 & 4.0 \\
Aspartic acid & 0.007 & 2857 & -4.5 \\
Glutamic acid & 0.009 & 2222 & -7.7 \\
Methionine & 0.012 & 1666 & -8.5 \\
Phenilalanine & 0.0165 & 1212 & -6.4 \\
Lysine & 0.0020 & 10000 & -7.7 \\
Co & 0.00023 & 86956 & 3.7 \\
$\mathrm{Zn}^{\text {II }}$ & 0.012 & 1666 & -2.4
\end{tabular}

His: histidine. 
to biological samples indicating good accuracy. Thus, the proposed method can be applied for the quantification in patients with histidinemia by direct analysis and with no laborious sample treatment.

Table 4. Recovery values for artificial and human urine

\begin{tabular}{lccc}
\hline Sample & $\begin{array}{c}\text { Spiked / } \\
\left(\mathrm{g} \mathrm{L}^{-1}\right)\end{array}$ & $\begin{array}{c}\text { Determined / } \\
\left(\mathrm{g} \mathrm{L}^{-1}\right)\end{array}$ & Recovered / \% \\
\hline \multirow{3}{*}{ Human urine 1 } & 3.0 & $3.2 \pm 0.7$ & 107.8 \\
& 6.5 & $6.5 \pm 0.4$ & 100.8 \\
& 8.0 & $10.2 \pm 0.9$ & 127.6 \\
\hline \multirow{3}{*}{ Human urine 2 } & 3.0 & $2.8 \pm 0.1$ & 92 \\
& 6.5 & $5.1 \pm 0.1$ & 78.7 \\
Artificial urine & 8.0 & $7.7 \pm 2.2$ & 96.9 \\
& 3.0 & $3.7 \pm 1.0$ & 124.3 \\
& 6.5 & $5.3 \pm 1.9$ & 81.5 \\
& 13.0 & $15.3 \pm 1.0$ & 117.3 \\
\hline
\end{tabular}

\section{Conclusions}

In the present study, it was possible to evaluate the direct interaction of GSH-CdTe QD with AAs according to their side chains. There was an effective interaction between His and $2.2 \mathrm{~nm}$ QDs, and a new analytical method was developed based on the direct AA-QD interaction. The method presented good selectivity, with analytical signal variations lower than 5\% in the presence of other AAs and metal ions in concentrations that can be found in urine. Besides, good recovery levels were achieved. These findings indicate that this method is a fast, selective and simple alternative for the His determination in abnormal contents in urine samples.

\section{Acknowledgments}

This study was financed in part by the Coordenação de Aperfeiçoamento de Pessoal de Nível Superior (CAPES, Brazil, finance code 001). The authors are also grateful to Fundação de Amparo à Pesquisa do Estado da Bahia (FAPESB), Petrobras and Conselho Nacional de Desenvolvimento Científico e Tecnológico (CNPq) for providing grants, fellowships and financial support.

\section{References}

1. Li, X.; Wong, C. C.; Tang, Z.; Wu, J.; Li, S.; Qian, Y.; Xu, J.; Yang, Z.; Shen, Y.; Yu, J.; Cai, Z.; Talanta 2017, 162, 285.

2. Martín Santos, P.; Sánchez, M. N.; Pérez Pavón, J. L.; Cordero, B. M.; Talanta 2020, 208, 120381.

3. Attia, M. S.; Biosens. Bioelectron. 2017, 94, 81.

4. Wasim, M.; Awan, F. R.; Khan, H. N.; Tawab, A.; Iqbal, M.; Ayesha, H.; Biochem. Genet. 2018, 56, 7.
5. Song, Y.; Xu, C.; Kuroki, H.; Liao, Y.; Tsunoda, M.; J. Pharm. Biomed. Anal. 2018, 147, 35.

6. Fingerhut, R.; Röschinger, W.; Heck, M.; Int. J. Neonatal Screen. 2016, 2, 2.

7. Freeto, S.; Mason, D.; Chen, J.; Scott, R. H.; Narayan, S. B.; Bennett, M. J.; Ann. Clin. Biochem. 2007, 44, 474.

8. Azuma, K.; Hirao, Y.; Hayakawa, Y.; Murahata, Y.; Osaki, T.; Tsuka, T.; Imagawa, T.; Okamoto, Y.; Ito, N.; Metabolites 2016, 6, 3.

9. Held, P. K.; White, L.; Pasquali, M.; J. Chromatogr. B: Anal. Technol. Biomed. Life Sci. 2011, 879, 2695.

10. Kaspar, H.; Dettmer, K.; Gronwald, W.; Oefner, P. J.; J. Chromatogr. B: Anal. Technol. Biomed. Life Sci. 2008, 870, 222.

11. Lorenzo, M. P.; Dudzik, D.; Varas, E.; Gibellini, M.; Skotnicki, M.; Zorawski, M.; Zarzycki, W.; Pellati, F.; García, A.; J. Pharm. Biomed. Anal. 2015, 107, 480.

12. Costa, B. M. C.; Prado, A. A.; Oliveira, T. C.; Bressan, L. P.; Munoz, R. A. A.; Batista, A. D.; da Silva, J. A. F.; Richter, E. M.; Talanta 2019, 204, 353.

13. Qi, J.; Li, B.; Wang, X.; Fu, L.; Luo, L.; Chen, L.; Anal. Chem. 2018, 90, 11827.

14. Li, J.; Fu, J.; Yang, Q.; Wang, L.; Wang, X.; Chen, L.; Analyst 2018, 143,3570 .

15. Wang, C.-y.; Shang, S.; Zheng, X.; Lei, P.; Han, J.; Yuan, L.; Li, Z.; Wang, R.; Gong, W.; Tang, J.; Yang, Y.; J. Braz. Chem. Soc. 2019, 30, 988.

16. Yu, J.; Wang, X.; Kang, Q.; Li, J.; Shen, D.; Chen, L.; Environ. Sci. Nano 2017, 4, 493.

17. Costa-Fernandéz, J. M.; Pereiro, R.; Sanz-medel, A.; TrAC, Trends Anal. Chem. 2006, 25, 207.

18. Molkenova, A.; Amangeldinova, Y.; Aben, D.; Sayatova, S.; Atabaev, T. S.; Sens. Bio-Sens. Res. 2019, 23, 100271.

19. Zhou, J.; Li, B.; Qi, A.; Shi, Y.; Qi, J.; Xu, H.; Chen, L.; Sens. Actuators, B 2020, 305, 127462.

20. Ensafi, A. A.; Kazemifard, N.; Rezaei, B.; Biosens. Bioelectron. 2015, 71, 243.

21. Cui, F.; Qiu, Q.; Peng, G.; Li, X.; Liu, X.; Chen, X.; Anal. Methods 2019, 11, 4137.

22. Sheng, Z.; Chen, L.; Anal. Bioanal. Chem. 2017, 409, 6081.

23. Li, G.; Fei, X.; Liu, H.; Gao, J.; Nie, J.; Wang, Y.; Tian, Z.; He, C.; Wang, J. L.; Ji, C.; Oron, D.; Yang, G.; ACS Nano 2020, 14, 4196.

24. Verma, N.; Singh, A. K.; Saini, N.; Sens. Bio-Sens. Res. 2017, 15,41 .

25. Rodrigues, S. S. M.; Ribeiro, D. S. M.; Soares, J. X.; Passos, M. L. C.; Saraiva, M. L. M. F. S.; Santos, J. L. M.; Coord. Chem. Rev. 2017, 330, 127.

26. Elmizadeh, H.; Soleimani, M.; Faridbod, F.; Bardajee, G. R.; Spectrochim. Acta, Part A 2019, 211, 291.

27. Nebu, J.; Anu, K. S.; Anjali Devi, J. S.; Aparna, R. S.; Aswathy, A. O.; Lekha, G. M.; Sony, G.; Microchem. J. 2019, 146, 12. 
28. Fu, H.; Hu, O.; Fan, Y.; Hu, Y.; Huang, J.; Wang, Z.; She, Y.; Sens. Actuators, B 2019, 287, 1.

29. Liu, H.; Li, M.; Jiang, L.; Shen, F.; Hu, Y.; Ren, X.; Spectrochim. Acta, Part A 2017, 173, 105.

30. Wu, P.; Yan, X. P.; Biosens. Bioelectron. 2010, 26, 485.

31. Che, Y.; Pang, H.; Li, H.; Yang, L.; Fu, X.; Liu, S.; Ding, L.; Hou, J.; Talanta 2019, 196, 442.

32. Huo, J. Z.; Li, X. S.; An, J. D.; Zhang, L. X.; Li, Y.; Du, G. X.; Wu, X. X.; Liu, Y. Y.; Ding, B.; J. Mol. Struct. 2020, 1201, 127214.

33. Tabaraki, R.; Abdi, O.; J. Fluoresc. 2019, 29, 751.

34. Liu, L.; Zhu, G.; Zeng, W.; Yi, Y.; Lv, B.; Qian, J.; Zhang, D.; Microchim. Acta 2019, 186, 98.

35. Forman, H. J.; Zhang, H.; Rinna, A.; Mol. Aspects Med. 2009, $30,1$.

36. Rogach, A. L.; Katsikas, L.; Kornowski, A.; Su, D.; Eychmüller, A.; Weller, H.; Ber. Bunsen Ges. Phys. Chem. 1996, 100, 1772.

37. Yu, W.; Qu, L.; Guo, W.; Peng, X.; Chem. Mater. 2003, 15, 2854.

38. Agência Nacional de Vigilância Sanitária (ANVISA); Resolução RDC No. 166, de 24 de julho de 2017, Brazil, available at https:// www.in.gov.br/materia/-/asset_publisher/Kujrw0TZC2Mb/ content/id/19194581/do1-2017-07-25-resolucao-rdc-n-166de-24-de-julho-de-2017-19194412, accessed in October 2020.

39. Chutipongtanate, S.; Thongboonkerd, V.; Anal. Biochem. 2010, $402,110$.

40. Laube, N.; Mohr, B.; Hesse, A.; J. Cryst. Growth 2001, 233, 367.

41. Rahman, M. F.; Hossain, J.; Kuddus, A.; Tabassum, S.; Rubel, M. H. K.; Rahman, M. M.; Moriya, Y.; Shirai, H.; Ismail, A. B. M.; J. Mater. Sci. 2020, 55, 7715.

42. Daramola, O. A.; Siwe Noundou, X.; Nkanga, C. I.; Tseki, P. F.; Krause, R. W. M.; J. Fluoresc. 2020, 30, 557.

43. Sousa, J. C. L.; Vivas, M. G.; Ferrari, J. L.; Schiavon, M. A.; J. Braz. Chem. Soc. 2018, 29, 2496.

44. Chen, H.; Wang, S.; Fu, H.; Xie, H.; Lan, W.; Xu, L.; Zhang, L.; She, Y.; Spectrochim. Acta, Part A 2020, 234, 118248.

45. Hao, L.; Chen, X.; Liu, D.; Bian, Y.; Zhao, W.; Tang, K.; Zhang, R.; Zheng, Y.; Gu, S.; Appl. Phys. Lett. 2020, 116, 10.

46. Dong, F.; Hu, K.; Han, H.; Liang, J.; Microchim. Acta 2009, 195.

47. Ramírez-Herrera, D. E.; Tirado-Guízar, A.; Paraguay-Delgado, F.; Pina-Luis, G.; Microchim. Acta 2017, 184, 1997.

48. Zhen, F.; Cao, Y.; Qin, X.; Wang, B.; Cities 2017, 60, 180.

49. H. R, C.; Schiffman, J. D.; Balakrishna, R. G.; Sens. Actuators, B 2018, 258, 1191.
50. Nelson, D. L.; Cox, M. M.; Lehninger Principles of Biochemistry, $5^{\text {th }}$ ed.; W. H. Freeman and Company: New York, USA, 2008.

51. Rezaei, B.; Shahshahanipour, M.; Ensafi, A. A.; Luminescence 2016, 31, 958.

52. Shen, Y.; Liu, S.; Wang, J.; Li, D.; He, Y.; Anal. Methods 2013, 5, 3228 .

53. Shen, Y.; Liu, S.; He, Y.; Luminescence 2014, 29, 176.

54. Soares, F. A.; Ceschi, M. A.; Franceschini, D. B.; do Canto, V. P.; Netz, P. A.; Campo, L. F.; J. Braz. Chem. Soc. 2019, 30, 2125.

55. Wu, Y.; Wang, Q.; Wu, T.; Liu, W.; Nan, H.; Xu, S.; Shen, Y.; ACS Appl. Mater. Interfaces 2018, 10, 43472.

56. Alves, J. Q.; Máximo, L. N. C.; Franco, L. P.; da Silva, R. S.; de Oliveira, M. F.; Anal. Methods 2019, 11, 185.

57. Chaves, O. A.; Teixeira, F. S. M.; Guimarães, H. A.; Braz-Filho, R.; Vieira, I. J. C.; Sant'Anna, C. M. R.; Netto-Ferreira, J. C.; Cesarin-Sobrinho, D.; Ferreira, A. B. B.; J. Braz. Chem. Soc. 2017, 28, 1229.

58. Shuai, L.; Chen, Z.; Fei, P.; Wang, Q.; Yang, T.; Luminescence 2014, 29, 79.

59. Kachooei, E.; Vaezzadeh, M.; Attar, F.; Zeinabad, H. A.; Saboury, A. A.; Kostova, I.; Falahati, M.; RSC Adv. 2016, 6, 105903.

60. Huang, S.; Qiu, H.; Liu, Y.; Huang, C.; Sheng, J.; Su, W.; Xiao, Q.; Colloids Surf., B 2015, 136, 955.

61. Fan, X.; Liu, S.; He, Y.; Colloids Surf., B 2011, 88, 23.

62. Movellan, K. T.; Wegstroth, M.; Overkamp, K.; Leonov, A.; Becker, S.; Andreas, L. B.; J. Am. Chem. Soc. 2020, 142, 2704.

63. Yannacone, S. F.; Sethio, D.; Kraka, E.; Theor. Chem. Acc. 2020, 139, 125.

64. Yang, J.; Liu, S.; Wang, L.; Hao, C.; Gong, H.; Shen, Y.; He, Y.; Spectrosc. Lett. 2015, 48, 351.

65. Hou, J.; Zhang, F.; Yan, X.; Wang, L.; Yan, J.; Ding, H.; Ding, L.; Anal. Chim. Acta 2015, 859, 72.

66. Hosseini, M.; Ganjali, M. R.; Vaezi, Z.; Arabsorkhi, B.; Dadmehr, M.; Faridbod, F.; Norouzi, P.; Sens. Actuators, B 2015, 210, 349.

67. Zheng, X.; Yao, T.; Zhu, Y.; Shi, S.; Biosens. Bioelectron. 2015, $66,103$.

68. Caldwell, K. L.; Sampson, E. J.; Miller, D. T.; Paschal, D. C.; Pirkle, J. L.; Morrow, J. C.; Ting, B. G.; Jackson, R. J.; Environ. Res. 1998, 76, 53.

Submitted: April 17, 2020

Published online: October 27, 2020 